\title{
A construção do tabagismo como problema de Saúde Pública: uma confluência entre interesses polliticos e processos de legitimação cientifica
}

Mary Jane Paris Spink'

Milena Silva Lisboa ${ }^{2}$

Flávia Regina Guedes Ribeiro ${ }^{3}$

SPINK, M.J.P.; LISBOA, M.S.; RIBEIRO, F.R.G. The social construction of smoking as a public health problem: a merging of political interests and scientific legitimation processes. Interface - Comunic., Saúde, Educ., v.13, n.29, p.353-65, abr./jun. 2009.

The aim of this article is to analyze some aspects of the social construction of smoking as a Public Health problem within the context of the formulation of transnational health policies. Adopting the constructionist perspective, we start from the premise that social phenomena are collective constructions that are historically situated and culturally contingent. We argue that the participation of diverse social actors that can act as spokespeople for specific communities - economic, political, social or scientific - is necessary so that smoking emerges as a Public Health problem. We propose that the current anti-tobacco scenario results from the merging of two narratives: one concerning the constitution of smoking as a health hazard, the other pertaining to the emergence of the transnational political scenario associated with a globalized society.

Keywords: Public Health. Smoking. Framework convention on tobacco control.
O objetivo deste artigo é analisar alguns aspectos do processo de construção do tabagismo como problema de Saúde Pública no contexto de formulação de políticas sanitárias transnacionais. Adotando a perspectiva construcionista, partimos do pressuposto de que fenômenos sociais são construções coletivas, historicamente situadas e culturalmente contingentes, e argumentamos ser necessária a participação de diversos atores sociais que atuem como porta-vozes de comunidades específicas - econômicas, políticas, sociais ou científicas - para a emergência do tabagismo como problema de Saúde Pública. Propomos que o atual cenário da luta antitabagismo resulta da confluência de duas narrativas: de um lado, a constituição do tabagismo como problema de saúde e, de outro, a emergência do cenário político transnacional próprio da sociedade globalizada.

Palavras-chave: Saúde Pública. Tabagismo. Convenção-quadro para controle do tabaco.

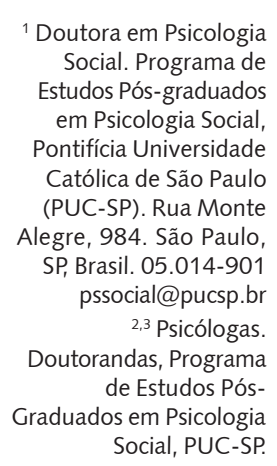




\section{Introdução}

O hábito de fumar tabaco é muito antigo e encontrado em diversos povos ao redor do mundo, exercendo diferentes funções culturais e econômicas. Segundo Rosemberg (1977), tal hábito se desenvolveu na Europa a partir do contato com os habitantes das Américas, que já utilizavam a folha de tabaco para fumar ou aspirar. No século XVII, a difusão do hábito de fumar, sobretudo na Europa, fomentou o valor monetário do tabaco no comércio internacional na mesma proporção que o seu cultivo.

No início do século XVII, foi criado, na Espanha, o precursor do cigarro a partir de rolos de tabaco envoltos em papel. Entretanto, somente em torno de 1840 foi inventado, na França, o cigarro, cuja produção em série facilitou a difusão e comercialização, atingindo consumidores de todas as classes sociais. Em pouco tempo o cigarro dominou o mercado tabagístico, passando a ser consumido em todos os continentes (Rosemberg, 2002). A partir de então, a produção e venda de cigarros começou a ser alvo de grandes corporações comerciais.

Apesar de ser um hábito enraizado em tradições culturais e históricas distintas e ser um produto cuja comercialização movimenta grandes dividendos, recentemente o tabagismo começou a ser considerado como problema de Saúde Pública, e sua prática enfaticamente desaconselhada e restringida. Segundo Rosemberg (2002), em meados do século XX, as análises econômicas indicam que os ganhos auferidos com a taxação sobre a venda deste produto eram inferiores aos gastos com assistência médica, aposentadorias, diminuição da produção laboral e encurtamento da expectativa de vida dos trabalhadores. Uma rede heterogênea de atores e ações começou, nesse momento, a ser articulada para elaboração de estratégias para a diminuição da produção e consumo do tabaco.

O objetivo deste artigo é analisar alguns aspectos do processo de construção do tabagismo como problema de Saúde Pública no contexto de formulação de políticas sanitárias transnacionais. Adotando uma perspectiva construcionista, partimos do pressuposto de que os fenômenos sociais são construções coletivas, historicamente situadas e contingentes (Loseke, Best, 2003; Spink, 1999). Tal postura requer a problematização de indicadores quantitativos, tomados como universais e como reflexos objetivos da realidade, seja por seus efeitos de essencialização de construções sociais, seja por considerá-los insuficientes para se entender o processo de definição de uma questão qualquer como problema social.

O argumento desenvolvido neste texto está sustentado nas teorizações de Rose (2001), Latour (2000) e Beck (1993). Nos apoiamos em Latour, sobretudo, para discutir o papel da literatura científica na construção de fatos. Latour (2000) nos esclarece que é preciso "algo mais" que referências a pesquisas e autoridades para configurar um tema como problema a ser estudado. Juntar e empilhar fotos, figuras, números, nomes e argumentos aos textos científicos e enlaçá-los uns aos outros constitui uma estratégia de legitimação de conhecimento. Entretanto, "fatos" não ficam confinados nas materialidades das produções textuais. Para o autor, não basta seguir os caminhos da construção do conhecimento a partir da formulação de sentenças ou enunciados que encerram um sentido geral sobre determinado assunto. É necessário que um determinado tema, como o tabagismo, instigue o interesse de diversos atores sociais, para atuarem como porta-vozes - isto é, falarem em nome de interesses de comunidades específicas, econômicas, políticas, sociais ou científicas. Contudo, os recursos para a ciência estão em poucos locais - nas laçadas e nos nós, fios e malhas tecidos por aqueles que se situam em lugares de poder privilegiados. Essas conexões permitem transformar recursos esparsos numa teia que parece se estender por toda parte. A noção de rede nos ajuda a conciliar os aspectos contraditórios da ciência médica enquanto propulsora da construção do tabagismo como problema de saúde, e a entender como tão poucas pessoas e instituições podem parecer "cobrir" o mundo e ter sucesso na formulação de políticas transnacionais.

Por sua vez, as reflexões de Rose (2001) sobre as transformações contemporâneas da biopolítica nos possibilitam argumentar que a configuração do tabagismo como problema de Saúde Pública se ancora, também, no contexto de ressignificação sanitária, que passa a priorizar a promoção da saúde como estratégia para fazer frente às dificuldades operacionais dos sistemas de atenção à saúde. Tal prioridade pode ser entendida com base nos processos de globalização, desterritorialização e individualização discutidos por Beck (1993), ao propor que vivemos hoje na sociedade de risco (e não mais na sociedade industrial). É nesse enquadre que tomaremos a "Convenção-Quadro" como exemplo de política 
sanitária transnacional que põe em movimento, concomitantemente, processos de construção de fatos científicos, responsabilização coletiva de governos e estratégias de promoção de saúde.

Propomos, assim, que a configuração do tabagismo como problema sanitário resulta da confluência de duas narrativas: de um lado, o empilhamento de evidências dos danos à saúde provocados pelo uso do tabaco acoplado às modernas concepções de promoção da saúde e, de outro, a emergência de um cenário político transnacional, próprio da sociedade globalizada, que possibilitou a formulação e ratificação desse primeiro tratado sanitário internacional.

\section{Uma primeira narrativa: a legitimação científica do controle social sobre o hábito de fumar}

O combate ao tabagismo, desde o princípio, fundamentou-se primordialmente em duas ações, com seus respectivos campos de força política. Um primeiro campo de ações teve, por foco, a produção científica que legitimou o tabagismo como problema de Saúde Pública, por meio de estudos sistemáticos realizados por cientistas autônomos e entidades médicas de renome internacional. Essa produção ocorreu de forma mais lenta no princípio, porém acelerou-se fortemente no século XX, abrindo espaço para um segundo campo de ações de combate: o campo jurídico. O Direito (nacional e internacional) desenvolveu legislação restritiva sobre a indústria tabagística e, sobretudo, o consumo do tabaco, a reboque do pensamento médico, suscitando ações na esfera estatal.

Vale ressaltar que, antes do domínio médico sobre o tabagismo instaurar-se, a questão do uso de tabaco já havia sido abordada pelas esferas do poder político. O primeiro escrito relacionado ao tema foi publicado em 1604. De autoria do rei Jaime I, da Inglaterra (Boeira, 2006), referia-se a taxações do comércio internacional de tabaco.

Nessa época, o poder de legitimação de conhecimentos ainda pertencia ao campo político e à figura do soberano. Como correlato no campo das legislações, não é surpresa que a primeira proibição do uso de tabaco, promulgada em 1642, tenha sido de autoria do Papa Urbano VIII e restrita aos eclesiásticos. Tratava-se de proibição fundamentada em aspectos morais, elaborada diante do aumento de prestígio do hábito entre clérigos (Rosemberg, 1977).

Datam deste mesmo século as primeiras publicações médicas. Uma das mais citadas e distorcidas publicações concerne à autópsia de um soldado fumante realizada pelo médico alemão Mander, a partir de uma crosta dura, de coloração escura, encontrada na calota craniana, interpretada, por ele, como resultado da fumaça que se difunde no cérebro depois de entrar pelo nariz. Esse estudo marca o início da preocupação médica sobre o tema. Em 1665, foi publicado outro curioso relato médico, de autoria de Simon Paul, acerca de interpretação de uma autópsia de fumante cujo cérebro teria dessecado como resultado do uso de tabaco, atingindo o tamanho de uma ervilha (Rosemberg, 1977).

Embora fosse tema de interesse da pesquisa médica, antes do século $X X$, a restrição ao tabagismo continuava sendo exercida por instituições religiosas. Dois estudos que se destacaram nesse ínterim foram as observações sobre saúde e tabaco realizadas por Rush, em 1798, e o estudo de Buisson com 68 fumantes doentes de câncer, publicado em 1859 (Rosemberg, 2002). Entretanto, nessa época, existia uma controvérsia acerca da nocividade do tabaco. Por exemplo, entre 1856 e 1857, a Revista Lancet publicou artigos de cinquenta médicos sobre tabagismo, entre os quais metade afirmava não existirem evidências suficientes para comprovar danos à saúde.

A partir da virada do século $X X$, o tabagismo passou ser um tema recorrente de pesquisa médica. Os estudos de Lombard e Doering relacionando o hábito de fumar ao surgimento de câncer, publicados em 1928, assim como os estudos de Pear sobre expectativa de vida, datados de 1938, são dois exemplos do modo como o tabaco estava sendo relacionado a problemas de saúde, delineados com base em estudos com amostras amplas. Nos Estados Unidos, em 1954, o relatório de autoria de Hammond e Horn (patrocinado pela American Cancer Society) teve enorme repercussão, chamando a atenção das autoridades sanitárias da época (Rosemberg, 1977). A partir desse momento, sociedades e associações científicas, com o apoio de órgãos de fomento estatais de países desenvolvidos, começaram a exercer um papel fundamental na história do tabagismo, na medida em que começaram a financiar pesquisas biomédicas e epidemiológicas de cunho quantitativo acerca dos danos à saúde relacionados ao uso de 
tabaco. O financiamento de pesquisas por sociedades e associações médicas é indício de quanto o tema já estava na ordem do dia.

A pesquisa de Hammond e Horn, realizada durante 44 meses, com 187.783 homens, sobre o hábito de fumar e sua correlação com taxas de mortalidade, é um exemplo desse foco. Um ano depois, foi entregue a John Fitzgerald Kennedy, então presidente dos Estados Unidos, o relatório conjunto da American Cancer Society, American Health Association, National Tuberculosis Association e American Public Health Association, contendo os principais resultados da pesquisa realizada por Hammond e Horn, requerendo a criação de uma comissão de estudos acerca dos problemas associados ao tabagismo.

Seguem-se outros esforços nesta mesma direção. Em 1962, na Inglaterra, foi publicado o $2^{\circ}$ Relatório do Royal College of Phisycians, intitulado Smoking and Health, estimando uma queda futura de $14 \%$ no consumo de tabaco no país, relacionada a medidas de combate ao hábito. Em 1964, o relatório da Comissão Consultiva do Diretor Geral da Saúde dos Estados Unidos, o Relatório Terry, elaborado com base na revisão de 30 mil publicações sobre tabaco e saúde, indicava os principais problemas de saúde relacionados ao hábito de fumar. Seu objetivo principal era a diminuição do consumo, e sua publicação teve o efeito de acelerar o abandono do hábito de fumar nos Estados Unidos e na Europa (Rosemberg, 2002).

Em 1966, Hammond e Horn publicaram os resultados de uma nova pesquisa, realizada com um milhão de homens e mulheres, com conclusões importantes relacionadas à saúde e mortalidade, que levou à aprovação de uma lei impondo a inscrição da mensagem "Atenção: fumar cigarros pode pôr em risco sua saúde" em maços de cigarro. Alguns anos depois, o Estado americano obrigava, por meio de mais uma lei, a publicação, na imprensa, de artigos e filmes antitabagismo, ações que se refletiram na queda dos índices de consumo de tabaco nos Estados Unidos. Por ocasião da publicação desses relatórios, trinta milhões de americanos haviam deixado de fumar (Rosemberg, 1977).

O Gráfico 1 permite visualizar o número crescente de publicações sobre riscos do tabaco à saúde no período entre 1900 e 2006. Os dados utilizados para cálculo da taxa de crescimento foram obtidos por meio de consulta ao Pubmed, realizada em 11 de janeiro de 2008. ${ }^{4}$

Para a consecução desse objetivo, utilizou-se o descritor smoking para busca somente no título do artigo. A pesquisa foi realizada por décadas, a partir de 1900.

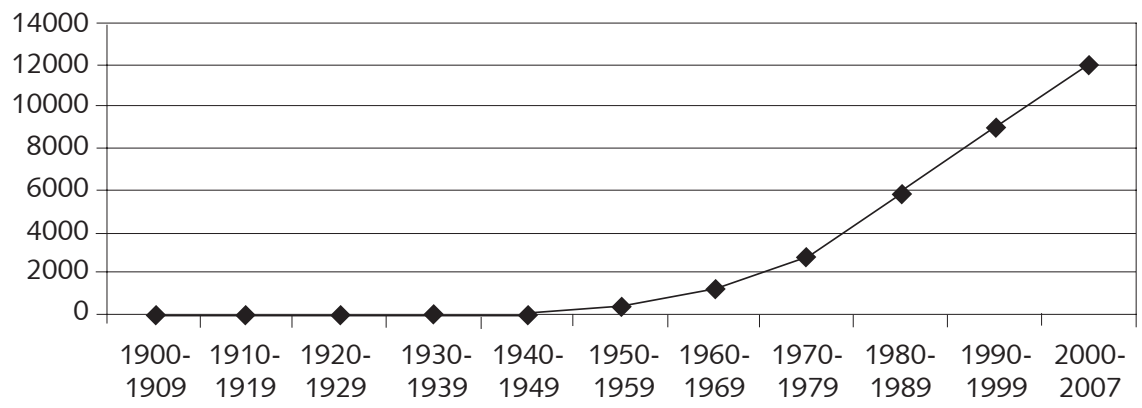

Gráfico 1. Número de artigos com o descritor "smoking" no título, por década.

${ }^{4} \mathrm{O}$ gráfico 1 permite visualizar o número sobre riscos do tabaco à saúde. Os dados utilizados para cálculo da taxa de crescimento foram obtidos por meio de consulta ao PubMed realizada em 28 de junho de 2007. Pubmed é um serviço da biblioteca nacional de medicina dos Estados Unidos que inclui 17 milhões de citações do Medline (base de dados de artigos médicos) e outros jornais e artigos das ciências da saúde desde 1950. A pesquisa nessa base de dados contou com a colaboração de Estevão Cabestré Gamba, bolsista do CNPq (apoio técnico). 
Até 1950 foram localizados apenas 26 artigos com smoking no título: um em 1900, outro em 1928, sete na década de 1930 e 17 na década de 1940. Já na década seguinte, foram localizados 343 artigos, aumentando para 1.195 na década de 1960, 2.851 na década de 1970, 5.836 na década de 1980, 8.992 na década de 1990, e 11.941 nos sete primeiros anos da década de 2000. Esse crescimento, até certo ponto, acompanha o incremento de artigos indexados no Pubmed, mas, se tomarmos a frequência relativa por base, há evidência de que o tabagismo tornou-se, paulatinamente, tema de interesse para a Saúde Pública. Ou seja, a porcentagem de artigos com smoking no título em relação ao número total de artigos indexados nessa base de dados aumenta de 0,012 na década de 1900 para 0,032 na década de 1950, e para 0,073, 0,117\%,0,179\% e 0,214\% nas décadas seguintes até o ano 2000.

A avalanche de dados sobre a associação entre fumo e uma diversidade de problemas de saúde coincide com a emergência dos conceitos modernos de promoção da saúde, movimento que tem seus fundamentos na década de 1970, com marcos, como o Relatório Lalonde (1974) e a Conferência de Alma Ata (1978). Esses primeiros esforços, assim como as propostas que as sucederam, procuraram romper com a visão biomédica e/ou comportamental de prevenção da saúde - uma centrada nos determinantes biológicos e fisiológicos da doença e a outra focalizada nos estilos de vida considerados inadequados para a saúde.

Essa nova abordagem de promoção da saúde vem sendo fortalecida nas Conferências Internacionais de Promoção da Saúde, apoiadas pela Organização Mundial de Saúde (OMS), realizadas: em Ottawa, Canadá, em 1986; em Adelaide, Austrália, em 1988; em Sundsval, Suécia, em 1991; em Jacarta, Indonésia, em 1998; no México, em 2000, e em Bancoc, Tailândia, em 2005.

A moderna concepção de promoção da saúde, segundo Westphal (2006), tem por base cinco princípios: (1) uma concepção holística de saúde, voltada à multicausalidade do processo saúde-doença; (2) a equidade como forma de enfrentar as desigualdades estruturais, relacionada, portanto, à distribuição desigual dos determinantes da saúde na população; (3) a intersetorialidade como estratégia para dar conta da complexidade do processo saúde-doença; (4) a participação social na definição das políticas, no controle social e na avaliação das ações e serviços, e (5) a sustentabilidade como forma de garantir ações duradouras. Embora seja uma postura politicamente correta, que adota uma concepção de saúde holística, multideterminada, processual e essencialmente voltada ao fortalecimento dos direitos básicos de cidadania, há críticas a essa abordagem, seja por ser uma prática altamente prescritiva que tende a impor estilos de vida considerados saudáveis, seja por reforçar a responsabilidade individual na manutenção da saúde, enfraquecendo a ação do Estado.

Configura, de qualquer forma, uma nova modalidade de biopolítica, que não tem mais como horizonte a aptidão da população como um todo orgânico. A saúde é hoje ressignificada em termos econômicos (dias de trabalho perdidos, custos previdenciárias etc.) ou morais (o imperativo contemporâneo de reduzir as iniquidades no campo da saúde). Nesse novo enquadre, permanecem as tarefas tradicionais do governo de populações (garantir a distribuição de água, constituir redes de esgoto, estabelecer controles sobre fármacos e alimentos etc.). Mas o Estado tenta se desvencilhar das responsabilidades adquiridas na modalidade do "Bem-estar Social", de sustentar cada membro individual da população em casos de doença ou acidente. Nesse novo enquadre, próprio à economia neoliberal, cada indivíduo é re-configurado como parceiro ativo na busca da saúde. Do "dever de saúde", próprio dos processos de disciplinarização associados ao higienismo, passamos a uma nova sensibilidade perante a saúde: o "desejo de saúde". A transferência da responsabilidade pela saúde para cada um de nós, fomentada, em parte, por ser re-situada em termos econômicos e morais, cria uma espiral que amplia paulatinamente o próprio sentido de saúde e o nosso desejo por saúde. Espiral que é gerida por meio da apresentação seletiva de informações e fomentada pelo ethos da comunicação.

A incorporação das informações sobre uso de tabaco no rol das preocupações cotidianas e sua transformação em práticas de prevenção têm sua contrapartida na noção de estilo de vida. Conforme afirmam Castiel e Vasconcellos-Silva (2006, p.82):

Um estilo de vida pode ser entendido como um conjunto relativamente integrado de práticas individuais que tanto estão voltadas para necessidades utilitárias como, ao mesmo tempo, conformam narrativas identitárias próprias. Além de 'como agir' referem-se a 'quem ser'. 
São 'hábitos' que, na modernidade tardia (ou sociedade de risco), estão cada vez mais descolados de padrões de comportamento associados a grupos e/ou a classes sociais.

Embora possam ser tomados como "padrões de consumo, manipulados pela chamada cultura de consumo de massa" (Castiel, Vasconcellos-Silva, 2006, p.83), com efeitos biográficos-identitários, o que está em pauta, quando se fala em estilos de vida, são "as escolhas e comportamentos com repercussões nos respectivos padrões e adoecimento das pessoas". É nesse enquadre que são realizadas enquetes e são definidos parâmetros que orientam as políticas públicas e os esforços de promoção da saúde, e que acabam por reforçar dois aspectos inter-relacionados: (1) a moralização dos estilos de vida arriscados $\mathrm{e}$ (2) a responsabilização individual.

\section{A segunda narrativa: a Organização Mundial da Saúde como cenário político transnacional}

No período após a Segunda Guerra Mundial, como parte dos esforços para garantir a paz e convivência harmoniosa entre as nações, foi criado um espaço de negociação e decisão com caráter transnacional: a Organização das Nações Unidas (ONU). Trata-se de um sistema de organizações setoriais voltadas a ações em campos específicos, como trabalho e saúde. Com a criação da Organização Mundial da Saúde (OMS) em 1948, diretamente ligada à ONU, o campo político de ações internacionais na área da Saúde modificou-se, transformando os modos como ações nacionais e internacionais eram construídas.

A OMS é uma agência internacional que tem como principais funções: propor diretrizes, conduzir, monitorar e avaliar as políticas de saúde em todo o mundo. A própria OMS apresenta a sua história ressaltando que sua constituição se deu no contexto político europeu após várias tentativas, realizadas a partir do século XIX, de organizar uma instituição de caráter internacional com objetivo de abordar os problemas sanitários do mundo (World Health Organization, 2002b).

Como contexto para a sua criação, vale citar que a epidemia de cólera ocorrida na Europa em meados do século XIX ofereceu o impulso necessário para a primeira Conferência Internacional de Saúde, realizada em Paris em 1851. O objetivo desse encontro, de criar o Consenso Internacional de Saúde, não teve sucesso (Matta, 2005). Seguiram-se outros esforços semelhantes, resultando na criação de diversas organizações de caráter internacional, tais como: o International Sanitary Bureau, em 1902, atualmente conhecido como Organização Pan-Americana de Saúde (OPAS); o Office International d'Hygiène Publique (OIHP), criado em Paris em 1907, e The Health Organization of the League of Nations, sediado em Genebra em 1919.

Tais organizações tinham por foco diferentes regiões do mundo e competiam em âmbito mundial por uma jurisdiçãa cada vez mais ampla, o que, de fato, não foi conseguido por nenhuma delas. Os desafios colocados ao campo da saúde no contexto pós-Segunda Guerra Mundial sustentaram a demanda para a constituição da OMS como única instituição intergovernamental de saúde ligada à recém-criada Organização das Nações Unidas.

Para aprovação de sua constituição em 1946, a OMS contou com a participação de 61 países. Em sua $1^{\text {a }}$ Assembléia Mundial, realizada em Genebra em 1948, delegações de 59 governos tornaram-se membros, aprovando sua constituição (Matta, 2005). Atualmente, 193 países participam como Estadosmembros por meio de delegações enviadas às Assembléias.

A Assembléia Mundial de Saúde é composta por representantes dos Estados-membros, e tem como principais objetivos: aprovar o programa e as diretrizes para o ano seguinte e decidir as principais questões políticas, além de eleger o diretor geral da OMS; supervisionar a política de financiamento, e avaliar e aprovar a proposta do programa orçamentário (Matta, 2005). É o órgão supremo de decisão e ocorre todos os anos no mês de maio, em Genebra. Dentre outras atribuições, elege os 34 Estadosmembros que formarão o Conselho Executivo da organização. Cada um dos 34 Estados-membros eleitos na Assembléia Mundial para formar o referido Conselho indica uma pessoa tecnicamente qualificada no campo da saúde para representá-lo. O Conselho tem por função efetivar as decisões e políticas da Assembléia de Saúde e assessorar e facilitar as ações da OMS (World Health Organization, 2002b). 
Em documentos oficiais da OMS, não há referência explícita ao modo como um tema relacionado à Saúde Pública (como o tabagismo) integra a pauta de uma Assembléia Mundial. Considerando a quantidade de problemas de Saúde Pública no mundo e a necessária restrição temática abordada em cada Assembléia Mundial, compreender como se dá esse processo de negociação, envolvendo a eleição de um problema específico como tema, é fundamental para entendermos os modos como o tabagismo constituiu-se progressivamente como problema de saúde, tornando-se alvo de políticas de Saúde Pública em nível mundial.

Hilgartner e Bosk (1988) sugerem que há uma hierarquização das questões sociais a serem investidas pelos programas de governo, sendo necessário compreender como, diante da multiplicidade de questões sociais que podem instigar a atenção social, algumas são privilegiadas, enquanto outras caem no ostracismo. Para Rosemberg (2000, p.86), compreender como um tema torna-se pauta da agenda das Organizações Multilaterais (como a OMS) requer a análise dos modelos teóricos e científicos envolvidos na definição de um tema como problemático, assim como "das necessidades internacionais e nacionais e seus interesses, de seus funcionários e dos Estados-membros que a integram e que têm maior poder de voto".

Em documento recente (Organização Mundial da Saúde, 2007) foi proposta uma estratégia mundial e um plano de ação que estabelecessem critérios, baseados em evidências e dados científicos, para orientar a eleição dos temas a serem discutidos nas Assembléias Mundiais. Para este objetivo, foi criado um "Grupo de Trabalho Intergovernamental sobre Saúde Pública, Inovação e Propriedade Intelectual", responsável, também, por deliberar quais temas constituem prioridades a partir do estabelecimento da ordem das necessidades de investigação e desenvolvimento. De modo a estabelecer a ordem de prioridade, a primeira medida deste plano de ação deveria ser a identificação das "lacunas existentes na investigação das enfermidades que afetam desproporcionalmente os países em desenvolvimento", pois "Um aprofundamento do conhecimento dos fatores determinantes das enfermidades é fundamental para orientar a investigação de novos medicamentos de uma maneira sustentável" (Organização Mundial da Saúde, 2007, p.2, tradução nossa).

Os critérios propostos incluem a diferenciação entre enfermidades: de tipo I, que ocorrem com igual distribuição em todos os países e não são privilegiadas pela OMS na hierarquização de sua pauta; de tipo II, que ocorrem em países desenvolvidos e em desenvolvimento, com maior prevalência nesses últimos, e de tipo III, que ocorrem única ou predominantemente em países em desenvolvimento. Vale enfatizar que tal iniciativa fundamenta-se na força argumentativa de evidências e dados empíricos provindos de pesquisas científicas, tornadas centrais como instâncias legitimadoras de critérios para a definição de prioridades. Aliados a tais evidências, estão implicados argumentos de caráter ético, relacionados à noção de equidade na definição das prioridades de investigação científica e implementação política das ações para países em desenvolvimento.

Entretanto, tal iniciativa aparece na história da OMS muito recentemente, instituindo, daí para frente, um processo sistemático de avaliação de prioridades. Antes disso, tal processo dizia respeito a trâmites internos nos quais a falta de transparência poderia fazer supor influências lobistas na decisão do que seria prioridade como problema de Saúde Pública em nível mundial. Essa hipótese fundamenta-se na participação de interesses econômicos e políticos em embates e processos de negociação que possivelmente interferiram na constituição do tabagismo como problema social na agenda governamental. Assim, é plausível que, diante dos efeitos econômicos dos prejuízos à saúde causados pelo tabaco nos países desenvolvidos, tenha ocorrido pressão para colocar o tabagismo na pauta de discussão da OMS. É possível argumentar, portanto, que, na história da constituição do tabagismo como problema social e pauta das ações da OMS, este foi tratado inicialmente como uma enfermidade de tipo I. A pressão econômica regida pela racionalidade mercantil dos estados nacionais mais poderosos pode ter contribuído para colocar o tabagismo como um problema a ser investido maciçamente pela OMS em suas ações em nível mundial. 
A convergência das duas narrativas: o processo de negociação da Convenção-Quadro para o controle do tabaco

Rosemberg (2000) aponta quatro fases do processo de construção de um tema como problema e, consequentemente, como assunto de pauta de uma organização internacional: (1) cria-se uma coalizão razoavelmente apoiada pelo secretário ou diretor da organização que define uma questão como "problemática"; (2) a coalizão defende o problema como sendo responsabilidade da organização; (3) a coalizão insere o problema nas reuniões de consulta e decisão; e (4) a organização cria estratégias de intervenção ou refuta a relevância do problema.

Apesar de tais fases não aparecerem de forma clara e explícita na constituição do tabagismo como problema na agenda da OMS, nos propomos a seguir as pistas históricas evidenciadas neste processo.

O tabagismo surgiu como tema das Assembléias Mundiais em 1970, depois da expansão de pesquisas e relatos científicos, ocorrida a partir da década de 1950 (vide Gráfico 1). Peritos da OMS, diante do intenso movimento no campo científico referente às relações entre o hábito de fumar e problemas de saúde, prepararam um relatório ("O hábito de fumar e a saúde") apresentado na $23^{a}$ Assembléia Mundial de Saúde, conseguindo aprovação e instituindo o tabagismo como objeto de ação da OMS.

É importante ressaltar que a relação entre a força argumentativa de pesquisas científicas e o consequente reconhecimento das Assembléias da OMS revela apenas parcialmente o campo de influências necessárias para o tratamento do tabagismo como problema de Saúde Pública mundial. Junto a isso, vale relembrar o papel das sociedades científicas e dos órgãos de fomento governamentais no financiamento de tais pesquisas. Além disso, o financiamento da própria OMS conta com duas fontes primárias (a contribuição regular dos Estados-membros e contribuições voluntárias), o que poderia fazer supor um campo de disputas e pressões políticas dentro desta organização para a definição das agendas e pautas das Assembléias Mundiais (Matta, 2005). Reiteramos, assim, a importância das conexões em rede (Latour, 2000) que possibilitam transformar recursos esparsos numa teia que parece se estender por toda parte.

O interesse dos governos em incentivar ações da OMS que diriam respeito ao controle do tabagismo, sobretudo a partir da segunda metade do século XX, está relacionado com os benefícios e custos do tabagismo ao Estado. Os impostos conseguidos por meio da taxação de produtos do tabaco diminuíram consideravelmente com o passar do tempo. O exemplo dos Estados Unidos revela claramente o declínio do valor das taxas sobre o produto, de 51\% em 1965 para 24\% em 2000, diminuindo a receita do Estado com a produção (World Health Organization, 2002a). Entretanto, como contrapartida, as indústrias de tabaco exerceram uma política de influência lobista, oferecendo, por exemplo, no ano 2000, mais de 37 milhões de dólares aos congressistas e candidatos federais e estaduais dos Estados Unidos para facilitar a defesa de seus interesses frente à campanha de controle do tabaco (World Health Organization, 2002a). O campo legislativo tornou-se arena de embates políticos entre a indústria de tabaco - com suas investidas para redução dos impostos sobre a produção e comercialização, e diminuição das proibições de consumo e propaganda -, e as organizações relacionadas à saúde, com ações voltadas, sobretudo, para a restrição do consumo.

Mesmo com o intenso investimento lobista das indústrias de tabaco, os governos, especialmente dos países desenvolvidos, começaram a sentir os efeitos dos gastos provindos do consumo exagerado e generalizado de produtos relacionados ao tabaco desde a década de 1970 (World Health Organization, 2002a). Por exemplo, em 2000, na maioria dos países do hemisfério norte, $25 \%$ de todas as mortes de homens foram relacionadas com o tabagismo. Como a produção em larga escala e o consumo de produtos fumígenos iniciou-se nos países desenvolvidos, neles os problemas de saúde mostraram-se mais precocemente. De acordo com dados publicados no Atlas do Tabaco (World Health Organization, 2002a), nos Estados Unidos, em 1999, foram gastos 76 bilhões de dólares com a assistência a saúde de fumantes e fumantes passivos, seis por cento de todo o gasto nacional com a Saúde Pública.

Desde 1970 até os dias atuais, o tema do tabagismo foi pauta frequente das Assembléias Mundiais. Em 1996, na 49a Assembléia Mundial, teve início o desenvolvimento das reflexões sobre o estabelecimento de uma convenção internacional antitabagista, com a proposta do Programa "Tabaco ou saúde" que seria apoiado pelas Nações Unidas. 
Quando, em 1998, a Dra. Gro Brundtland assumiu a diretoria geral da OMS, a campanha antitabagista passou a ter prioridade nas ações e discussões em nível mundial. A essa altura, inúmeras organizações filantrópicas e governamentais, regionais e internacionais, já uniam esforços para o controle do tabagismo, considerado, então, endemia mundial.

Porém, a constituição do tabaco como problema de saúde não se deu apenas por meio da divulgação de índices quantitativos. Para Best (1987), os atores interessados em tornar pública uma questão social utilizam diferentes recursos e estratégias discursivas, para ganhar o reconhecimento de sua gravidade pela sociedade, garantindo sua legitimação como problema social. A Dra. Gro Brundtland, por exemplo, utilizando uma retórica de caráter ativista, recorreu aos estudos acerca do conhecimento das pessoas sobre os problemas de saúde causados pelo uso do fumo para sustentar seu apelo à cessação da prática de fumar e convidar seus interlocutores a "lutarem" contra o fumo. Em seus discursos, utilizou vocabulário e metáforas militares para convencer a todos sobre a gravidade do problema e convidá-los para a "luta".

De acordo com Best (1987), os atores sociais interessados em legitimar um problema social desenvolvem uma retórica de caráter dramático, com a intenção de acentuar a necessidade de mobilização e indignação e defendê-lo como problema social a ser investido por políticas sociais. No ano de 2000, no discurso "Não se deixe enganar, o cigarro mata" (Tobacco kills Don't be duped), proferido na Tailândia, a Dra. Gro apresentou a indústria do tabaco como a grande vilã a ser combatida na luta contra o tabagismo e explicitou as estratégias usadas pelas indústrias para tornar as pessoas dependentes do tabaco. Nesse discurso, apresentou também o tabagismo como uma "doença publicitária", culpabilizando, além das indústrias do tabaco, as empresas de comunicação e marketing que encorajam o seu consumo. Seu argumento vitimiza os cidadãos, considerados "escravizados" pela campanha mobilizada pelas entidades pró-tabaco. Esse argumento foi estendido a grupos populacionais específicos: crianças e jovens, considerados mais vulneráveis às influências das indústrias tabagistas, e os fumantes passivos, foco de discurso intitulado "Vamos limpar o ar" (Second-Hand Smoke: Let's clean the air), proferido no ano de 2001.

Nesse cenário, a Dra. Gro apresenta-se como porta-voz (Latour, 2000) legítima dos interesses daqueles que situavam o tabagismo como problema de Saúde Pública. Ou seja, ela representou aqueles que a escolheram para falar em nome da causa e dar visibilidade aos argumentos que põem em tela o combate à prática de fumar.

A partir da gestão da Dra. Gro na diretoria da OMS, foram mobilizadas iniciativas confluentes para a elaboração de uma convenção mundial para o combate ao tabagismo, configurando o primeiro tratado internacional de saúde, chamado "Convenção-quadro para o controle de tabaco", negociado até o ano de 2003 por 192 países. Como se configurava como tratado internacional, havia a exigência de os países signatários ratificarem a convenção como modo de participar das Conferências das Partes, instância de discussão e implementação das futuras ações.

Em 1999, na 52a Assembléia Mundial, foi criado um grupo de trabalho sobre a Convenção, aberto a todos os Estados-membros, organizações de integração econômicas regionais e observadores. No ano 2000, houve uma audiência pública na ONU, com participação de organizações não-governamentais (ONG's) e representantes do setor de fumo. Desde então, cinco audiências públicas foram realizadas submetendo o texto à avaliação dos participantes. Em maio de 2003, na 56 a Assembléia Mundial, foi aprovado o texto final da Convenção-Quadro, adotado por consenso, mas necessitando de ratificação por quarenta países para tornar-se uma legislação internacional (WHO, 2003).

\section{O Brasil na "luta" contra o tabagismo: \\ o processo de ratificação da Convenção-Quadro}

Desde 1986, leis brasileiras vêm sendo redigidas tentando frear o consumo de tabaco no país. Para conseguir essa redução, foi necessário, a partir de 1986, aprovar legislação que contemplasse ações de caráter proibitivo e restritivo de consumo de tabaco, assim como outras de caráter educativo, estas elaboradas inicialmente de forma mais tímida. Assim, mesmo antes da elaboração do texto final da Convenção-Quadro, foi criada, em 1999, a "Comissão Nacional para Implementação da Convenção- 
Quadro para Controle de Tabaco", de caráter interministerial, com o objetivo de construir uma agenda do Estado para o cumprimento das diretrizes previstas.

Apesar da pronta assinatura brasileira da Convenção, o processo de ratificação foi lento e burocrático, envolto em interesses divergentes, quase sempre obscurecidos pela falta de transparência dos processos de decisão. De acordo com Gewehr (2006), o processo de ratificação no Brasil expôs claramente os interesses políticos e econômicos implicados na aprovação na Convenção-Quadro, dispondo os atores envolvidos em duas posições divergentes: um lado comprometido com os interesses da indústria tabagista, protagonizado pela Associação dos Fumicultores do Brasil (Afubra), e outro defendendo a promoção e defesa da Saúde Pública, representado pelo Instituto Nacional de Câncer (Inca).

Como as diretrizes da Convenção-Quadro voltam-se para a diminuição do consumo, os efeitos a longo prazo, na produção das lavouras, começaram a ser esperados. Alarmada com essa possibilidade, a Afubra divulgou informações exageradas sobre a extinção de postos de trabalho, pressionando com isso os senadores a não ratificarem a Convenção-Quadro. Foi necessária a realização de audiências nas principais regiões produtoras do país, em Iratu (PR), Camaquã (RS), Florianópolis (SC) e Cruz das Almas (BA), além das realizadas com representantes do Governo, para garantir que os produtores de fumo não seriam prejudicados. Todo esse processo resultou em atraso na tramitação. Deste modo, mesmo com uma legislação considerada das mais avançadas do mundo, a ratificação da Convenção-Quadro só se deu oito meses após sua ratificação na OMS, ocorrida em 27 de fevereiro de 2005 (Brasil, 2004).

É interessante ressaltar que a ratificação brasileira se deu com o depósito de um anexo: uma declaração interpretativa dos artigos $4^{\circ}, 17^{\circ}$ e $26^{\circ}$ como salvaguarda dos produtores de fumo. A partir de então, com o lançamento do "Programa de Apoio à Diversificação Produtiva das Áreas Cultivadas com Fumo", o governo brasileiro apoia quatro eixos estratégicos: financiamento, acesso à tecnologia, agregação de valor à produção local e garantia de comercialização.

Atualmente, segundo Meireles (2006), morrem no Brasil cerca de duzentas mil pessoas por ano por conta do tabagismo, número considerado alarmante. As ações posteriores à Convenção tentam, por meio do Programa Nacional de Controle do Tabagismo, realizado pelo Inca (Brasil, 2001), diminuir índices de consumo e assegurar maior qualidade de vida a fumantes, ex-fumantes e não-fumantes, com as seguintes medidas: garantindo espaços livres de fumo; proibindo a venda a menores de 18 anos; coibindo e regulando o incentivo ao fumo por propagandas; alertando sobre os riscos do fumo passivo; educando quanto aos malefícios de fumar, e premiando ações preventivas e educativas destinadas a todo tipo de público, sobretudo crianças e adolescentes.

\section{Considerações finais}

Argumentamos, neste artigo, que a configuração do tabagismo como problema sanitário resulta da confluência de duas narrativas: de um lado, a constituição do tabagismo como problema de Saúde Pública; de outro, a emergência de um cenário transnacional, próprio da sociedade globalizada, que possibilitou a ratificação do primeiro tratado internacional na área da Saúde Pública, voltado ao controle do tabagismo.

A primeira narrativa se dá na interface entre processos de legitimação científica, ancorados na produção de evidências epidemiológicas e a ressignificação da saúde na vertente da promoção da saúde. No que diz respeito às já consolidadas evidências provenientes de pesquisas, Latour (2000) nos esclarece que é preciso "algo mais" que referências a pesquisas e autoridades para configurar um tema como problema a ser estudado. É preciso empilhar fotos, figuras, números, nomes e argumentos aos textos científicos e enlaçá-los uns aos outros de modo a criar uma "caixa-preta" : no caso, a afirmação do tabagismo como problema de saúde.

Quanto à promoção da saúde, embora sua versão mais atual adote uma concepção de saúde holística, multideterminada, processual e essencialmente voltada ao fortalecimento dos direitos básicos de cidadania (Westphal, 2006), há temor que dê respaldo a uma abordagem por demais prescritiva e passível de exacerbar os processos de individualização que marcam a modernidade tardia, reforçando a responsabilidade individual e liberando o Estado (em sua versão neoliberal) de parte de suas 
responsabilidades perante a saúde da população (Spink, 2007). No dizer de Rose (2001), a biopolítica se tornou bioeconomia. O Estado perde, assim, sua função pastoral - forma de poder voltada ao bemestar do rebanho como um todo. Embora retenha a responsabilidade adquirida nos séculos XVIII e XIX pelas condições gerais de saúde da população, procura livrar-se das responsabilidades adquiridas no início do século XX, de assegurar os indivíduos frente às doenças e acidentes. Vê-se, portanto, uma intensificação das estratégias de promoção da saúde, relacionadas, por exemplo, com o "estilo de vida": "Todo cidadão deve agora tornar-se um parceiro ativo na busca da saúde, aceitando sua responsabilidade por assegurar seu bem-estar" (Rose, 2001, p.6).

A segunda narrativa se insere em outra rede de complexidades. Concerne, antes de tudo, aos processos de globalização que, segundo Beck (1993), têm por principal característica o entrelaçamento de relações e eventos sociais que estão distantes dos contextos locais. Essa articulação de relações sociais que atravessam vastas fronteiras de tempo e espaço - o movimento de pessoas, de produtos e de informação - tem consequência, também, no que diz respeito aos riscos contemporâneos, incluindo, aí, a questão do tabaco. Beck usa a expressão "sociedade de risco" para pontuar a complexidade dos riscos modernos, seja pela natureza dos riscos - enfatizando a presença crescente dos riscos manufaturados, produtos dos desenvolvimentos da ciência e tecnologia -, seja pela progressiva tendência à desterritorialização e globalização desses riscos.

Emerge daí uma nova sensibilidade: a percepção crescente de que os riscos são sistêmicos, acompanhada da consciência de sua imponderabilidade e da necessidade de mecanismos igualmente complexos de sua gestão. Lidar com processos sociais globalizados requer a criação de espaços de interlocução capazes de pactuar de modo a promover ações que tenham a humanidade por foco, e não apenas a riqueza de nações específicas. É nesse novo clima de compartilhamento que se inserem esforços de definição de tratados como a Convenção-Quadro, que se destinam a definir questões como "problema" e deliberar sobre formas de conduta perante as mesmas.

Ao discutirmos a Convenção-Quadro, procuramos mostrar que é necessário que um determinado tema, como o tabagismo, instigue o interesse de diversos atores sociais para atuarem como porta-vozes. Porém, como os recursos para a ciência estão em poucos locais, o sucesso de uma política de cunho transnacional precisa ser entendido na perspectiva das redes discutidas por Latour (2000). São as conexões em rede que permitem transformar recursos esparsos numa teia que parece se estender por toda parte e permitem entender como tão poucas pessoas e instituições podem parecer "cobrir" o mundo e ter sucesso na formulação de políticas transnacionais.

A confluência dessas duas narrativas - de construção do tabaco como problema de Saúde Pública e da ratificação da Convenção-Quadro - constituiu o cerne da reflexão feita neste artigo. Na perspectiva ético-política associada à abordagem construcionista, o que está em pauta é a compreensão dos processos que possibilitam colocar problemas sociais de interesse coletivo e transnacional, como a pobreza e os agravos à saúde, na agenda de discussão de organismos internacionais e transformá-los em diretrizes de ação. É, sobretudo, nesta acepção que a Convenção-Quadro é de particular interesse por evidenciar os processos que levam da construção de algo como problema para soluções com caráter transterritorial. 


\section{Colaboradores}

Todas as autoras participaram igualmente na elaboração do manuscrito.

\section{Referências}

BECK, U. Risk society: towards a new modernity. London: Sage, 1993.

BEST, J. Rhetoric in claims-making: constructing the missing children problem. Soc. Probl., v.34, n.2, p.101-21, 1987.

BOEIRA, S.L. Indústria de tabaco e cidadania: confronto entre redes organizacionais. Rev. Admin. Empr., v.46, n.3, p.28-41, 2006.

BRASIL. Ministério da Saúde. Secretaria da Saúde. Secretaria de Atenção à Saúde. Instituto Nacional de Câncer. A ratificação da Convenção-Quadro para o controle do tabaco pelo Brasil: mitos e verdades. Rio de Janeiro: INCA, 2004.

Ministério da Saúde. Instituto Nacional de Câncer. Coordenação de Prevenção e Vigilância - CONPREV. Programa Nacional de Controle do Tabagismo e outros fatores de risco-Brasil. Rio de Janeiro: INCA, 2001.

CASTIEL, L.D.; VASCONCELLOS-SILVA, P.R. A noção 'estilo de vida' em promoção da saúde: um exercício crítico de sensibilidade epistemológica. In: BAGRICHEVSKY, M. et al. (Orgs.). A saúde em debate na educação física. Blumenau: Nova Letra, 2006. p.6792. v.2.

GEWEHR, A.O. Derrotamos o lobby e o proselitismo político. 2005. Disponível em: $<$ http://www.fetrafsul.org.br/

index. php?option $=$ com_content\&task=view\&id=191\&ltemid=>. Acesso em: 10 set. 2007.

HILGARTNER, S.; BOSK, C.S. The rise and fall of social problems: a public arena model. Am. J. Sociol., n.94, p.53-78, 1988.

LATOUR, B. Ciência em ação: como seguir cientistas e engenheiros sociedade afora. São Paulo: Editora Unesp, 2000.

LOSEKE, D.; BEST, J. Introduction to section I. In: (Orgs.). Social problems: constructionist readings. New York: Aldine de Gruyter, 2003. p.3-5.

MATTA, G. A Organização Mundial da Saúde: do controle de epidemias à luta pela hegemonia. Trab. Educ. Saude, v.3, n.2, p.371-96, 2005.

MEIRELES, R.H.S. A ratificação da Convenção-Quadro para o controle do tabaco pelo Brasil: uma questão de saúde pública. J. Bras. Pneumol., v.32, n.1, p.ii-iii, 2006.

ORGANIZACIÓN MUNDIAL DE LA SALUD. Informe de la primera reunión Ginebra, 4-8 de diciembre de 2006. Genebra, 2007. Disponível em: < http://www.who.int/gb/ phi/pdf/igwg1/A_PHI_IGWG1_6-sp.pdf>. Acesso em: 10 maio 2007.

ROSE, N. The politics of life itself. Theo., Cult. Soc., v.18, n.6, p.1-30, 2001.

ROSEMBERG, F. Uma introdução ao estudo das organizações multilaterais no campo educacional. In: KRAWCZYK, N.; CAMPOS, M. M.; HADDAD, S. (Orgs.). O cenário educacional latino-americano no limiar do século XXI: reformas em debate. Campinas: Autores Associados, 2000. p.63-93.

Pandemia do tabagismo: enfoques históricos e atuais. São Paulo: Secretaria da Saúde, Centro de Vigilância Epidemiológica, 2002.

Tabagismo: sério problema de Saúde Pública. Separata: Revista da PUC-SP, v.XLVII, n.93, p.105-24, 1977. 
SPINK, M.J.P. Sobre a promoção da saúde: tensões entre risco na modalidade da aventura e as estratégias contemporâneas de biocontrole. In: JACÓ-VILELA, A.M.; SATO, L. (Orgs.). Diálogos em Psicologia Social. Porto Alegre: ABRAPSO SUL, 2007. p.345-60.

(Org.). Práticas discursivas e produção de sentidos no cotidiano: aproximações teóricas e metodológicas. São Paulo: Cortez, 1999.

WESTPHAL, M. Promoção da saúde e prevenção da doença. In: CAMPOS, G.W.S. et al. (Orgs.). Tratado de Saúde Coletiva. São Paulo: Hucitec, 2006. p.635-67.

WORLD HEALTH ORGANIZATION. The framework convention on tobacco control: a primer. Genebra: WHO Document Production Services, 2003.

The tobacco atlas. Genebra: WHO Document Production Services, 2002a.

History of WHO and international cooperation in public health. 2002b.

Disponível em: <www.who.int/aboutwho/en/history.htm>. Acesso em: 03 jul. 2007.

SPINK, M.J.P.; LISBOA, M.S.; RIBEIRO, F.R.G. La construcción del tabaquismo como problema de Salud Pública: una confluencia entre intereses políticos y procesos de legitimación científica. Interface - Comunic., Saúde, Educ., v.13, n.29, p.353-65, abr./jun. 2009.

El objeto de este artículo es el de analizar algunos aspectos del proceso de construcción del tabaquismo como problema de Salud Pública en el contexto de formulación de políticas sanitarias trans-nacionales. Adoptando la perspectiva construccionista, partimos del presupuesto de que fenómenos sociales son construcciones colectivas, históricamente situadas y culturalmente contingentes y argumentamos la necesidad de participación de diversos actores sociales que actúen como portavoces de comunidades específicas - económicas, políticas, sociales o científicas, para la emergencia del tabaquismo como problema de Salud Pública. Proponemos que el ámbito antitabaquista actual resulta de la confluencia de dos narrativas: una tiene por foco la construcción del tabaquismo como problema de salud y la otra la emergencia del ámbito trans-nacional propio de la sociedad globalizada.

Palabras clave: Salud pública. Tabaquismo. Convención-cuado para control del tabaco. 